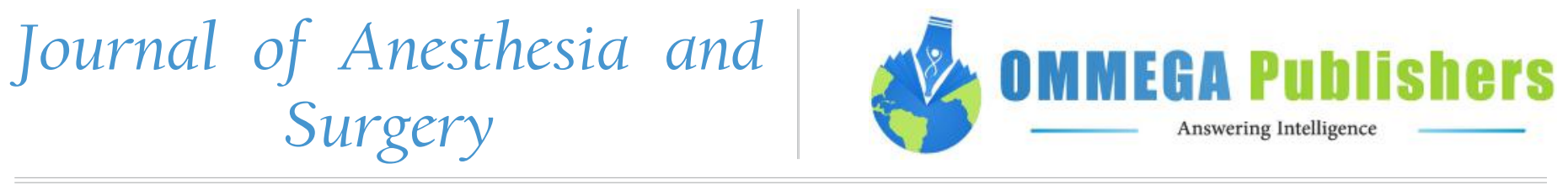

Mini Review Article

\title{
New Program for Estimation of Degree of the Patient's severity
}

\author{
Andrey Belousov* \\ Laboratory of Applied Nanotechnology of Belousova, Kharkov Medical Academy of Postgraduate Education, Ukarine \\ *Corresponding author: Andrey Belousov, Lenina, 31-v, fl. 32, Kharkov, 61072, Ukraine, Tel: +38050-915-18-89; \\ E-mail: an.belousov2012@yandex.ua
}

\begin{abstract}
Based on parameters of the previously developed by the author universal analytical system of physiological condition of the body (PHUAS) a new algorithm for assessing of the patient's severity was proposed. Algorithm of computer program allows identify risk groups among patients in severity general condition automatically quickly and objectively. Also, it permits to determine optimal and efficient options of prevention and treatment, avoid in-depth examinations that can save both time and money. The data that were obtained could be used for the subsequent correlation with various factors that influencedon organism. These factors were such as ecology, nutrition, medications, vaccine, methods of intensive therapy, pharmacotherapy, etc. In general, the proposed algorithm allows estimating the severity of the patient's health, improving welfare of the population in terms of underfunding by means objective and rapid examination of a large number of people.
\end{abstract}

Keywords: Algorithms; Program of PHUAS; Assess; Physiological condition; Severity; Prevention; Efficiency of treatment; Correlation

\section{Introduction}

At present, the doctor's arsenal has few tens of rating scales, most of which have been used in the practice of intensive care units. Some of them have received global popularity and have been used in virtually all countries of the world (such as APACHE, SAPS, TISS), others (MPM, TOSS) have been applied more rarely ${ }^{[1,2]}$. Objective assessment of the severity of the patient's condition is a necessary tool for decision-making on management of patients, solving the problems of transporting them and the optimum placement of patient care (emergency department, specialized department, ICU, etc.), comparison the outcomes of patients depending on the therapies and quality of care. The latest versions of rating scales (APACHE III, SAPS II) were build on new principles of construction - selection and weighting of variables, which based on statistical modeling techniques and the risk of death was estimated by means multiple logistic regression model ${ }^{[3]}$.

Today most of hospitals district and city centers have the significant deficiency of technical equipment, so using of theseevaluation systems are objectively impossible. Many scoring systems are very time-consuming and cumbersomethemselves, and, therefore, they need to be updated and improvedconstantly.Besides, each of these systems scoring has its own specific variables for assessing of the severity of the disease. It determines not only their specifics butsubjective approach in assessment of the parameters.

Therefore, every physician who has used a particular evaluation system in practiceoften finds out inconsistency between of clinical severity of patient and result of assessment. Due this fact, the forecast of mortality is not always veridi-
Citation: Andrey B. New Program for Estimation of Degree of the Patient's severity. (2015) J Anesth Surg 2(1): 40-42.

Received date: March 30, 2015

Accepted date: June 23, 2015

Published date: June 26, 2015

DOI: $10.15436 / 2377-1364.15 .016$
cal.Another important disadvantage of the above evaluation systems is the inability to conduct a complex analysis of clinical and laboratory data. In 1990, in Leningrad, on the basis of LMT the software-Research Module for analysis of clinical and laboratory data (GEMA) was first developed. The first version of intellectual medical system was created on this basis in 1993 . This software package was namedOMIS ${ }^{[4]}$.

However, intelligent computer OMISsystem couldn'tbe objective in general cases. The computer system wasn'table to take into account all nuances of individual clinical and laboratory data. New universal analytical evaluative system of the physiological state of the organism (PHUAS) that was created by the author was an attempt of combining the positive aspects of the above evaluative systems ${ }^{[5]}$ (Figure 1).

Copy rights: (C2015 Andrey B. This is an Open access article distributed under the terms of Creative Commons Attribution 4.0 International License. 
Figure 1: Analytical PHUAS system (fragment)

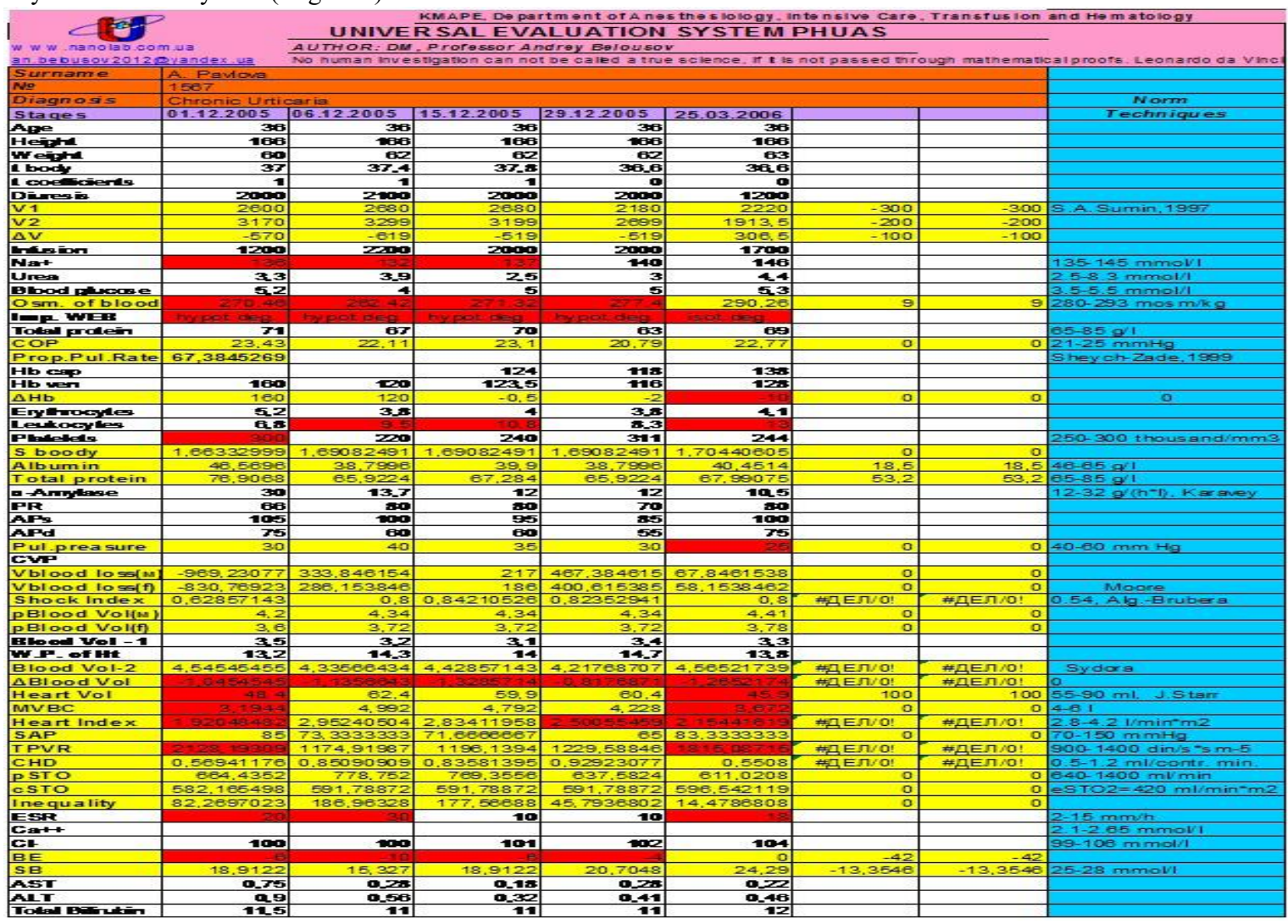

Analytical PHUAS systemcontains different formulas that are used in medicine (for example,Astrup, Starr, De-Rittis, Algover-Bruber, Sydore, Sheych-Zade, Moore, Sumin and others). The PHUAS system allows to receive 74 integral parameters from 54 obtained analytical parameters by using of software Excel. The data obtained from 128 indicators allow the practitioner to assess objectively the overall picture of the reaction of compensatory mechanisms of physiological and pathophysiological processesand also reliably identify the basic syndrome disease, observe of the pathological process and effectiveness of the therapy.The data of evaluative system that have been obtainedin dynamics after four measurements transfer automatically to the table for calculating of the coefficient ofcorrelation, with reliability $\mathrm{p}<0.05$. It allows to reveal the basic pathogenic links of the disease, key clinical and biochemical parameters (Figure 2).

Figure 2: Calculation of the coefficient of correlation by using PHUAS (fragment)

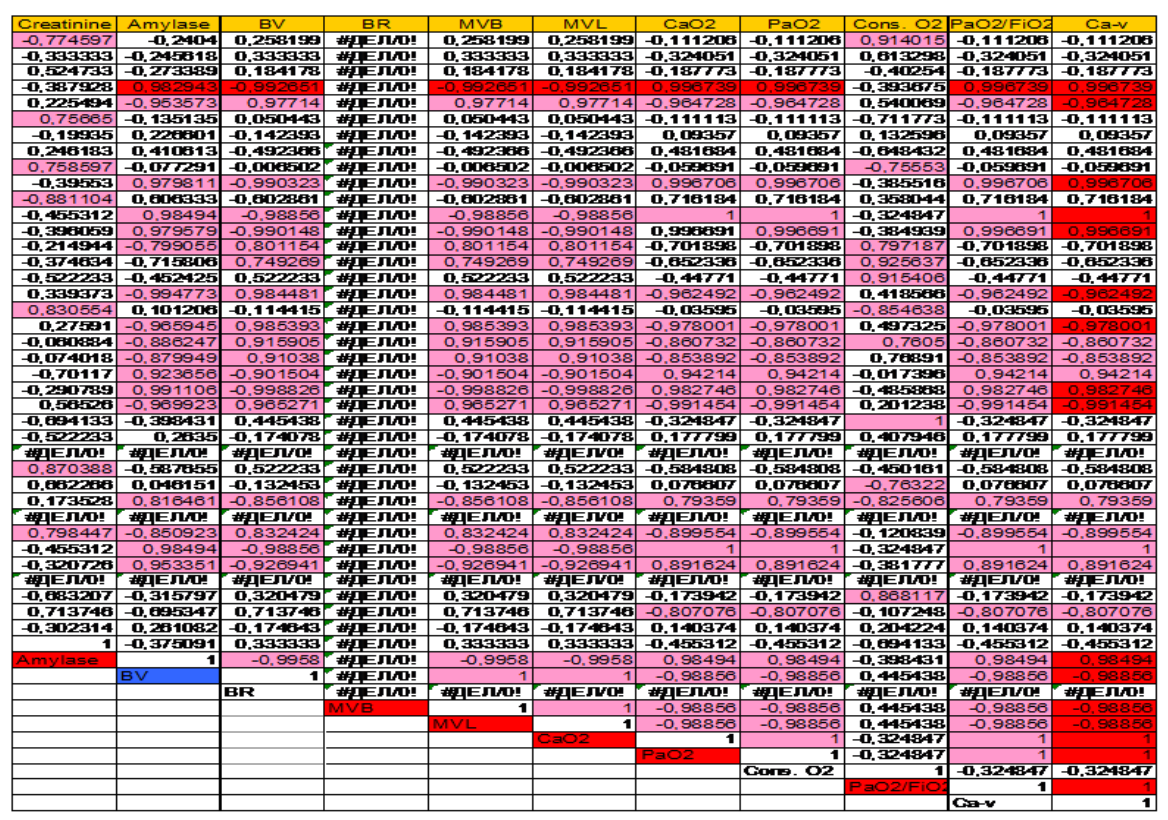

The PHUAS system calculates automatically for individual patient correction of water-electrolyte and acid-base balance, creatinine clearance, and in case of the predicted blood loss - volume of infusion solutions for hypervolemichemodilution (Figure 3). 
Figure 3: Calculation of corrective therapy (fragment of PHUAS)

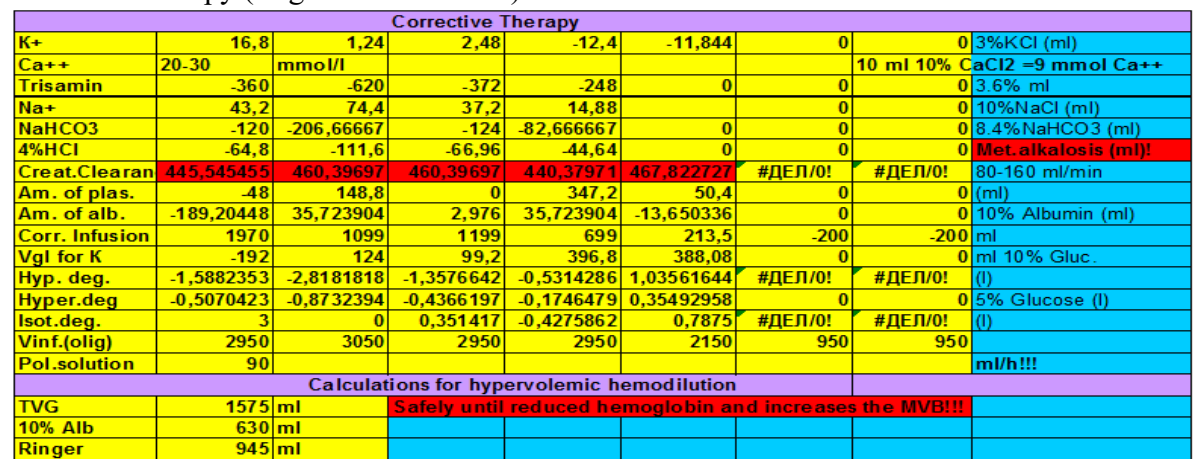

Effectiveness of the program requires of basic clinical and biochemical parameters of the body that includes common clinical and biochemical analysis of venous and capillary blood, urine.Alsoit needs information about the water exchange in day, weight, arterial pressure, respiratory rate, heart rate and body temperature. When the patient is on artificial ventilation, it requires the mode of ventilation of lungs. Based on assessment of the PHUAS program the physician could determine objectively and reliably the main syndrome of disease, the most important biochemical parameters in individual patients and alsoapply these data for estimation of algorithm of the patient'sseverity (Figure 4).

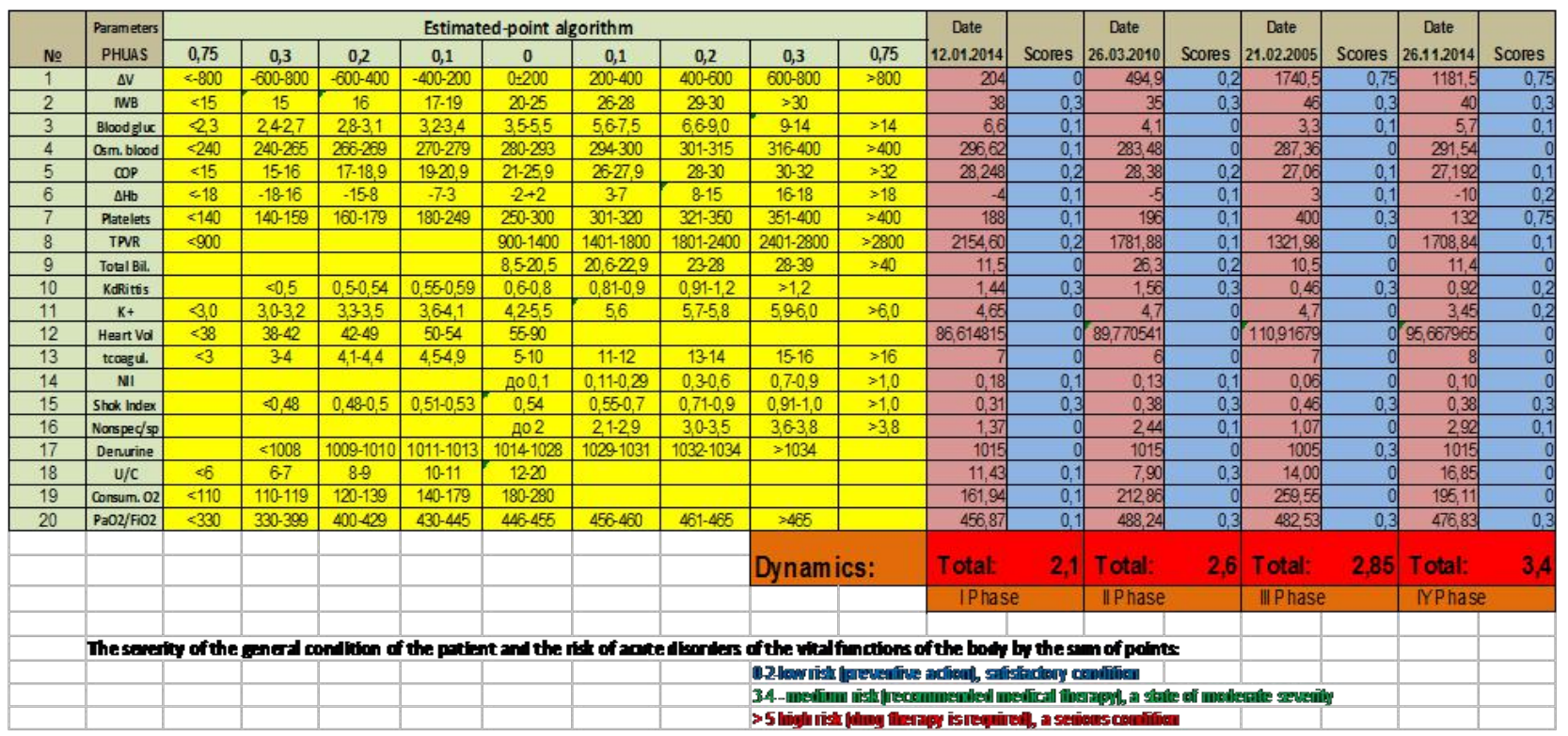

The developed algorithm scoring allows determining the risk of danger of the disease, identifying the degree of clinical severity of the general condition of the patient, finding out the best financially and clinically effective way of prevention and treatment, complex assessing of the quality of the therapeutic and preventive measures.

The main components of the program are systemic approach, real access to health care and social rehabilitation, regardless of gender, age and social status. Also, PHUAS provides independence, the constancy of the diagnostic and therapeutic processes, allows control the volume, quality and timeliness of delivery of health services and their compliance with medical standards.

Also, the advantage of the program is not only fast and objective examination of large number of people, early identification of risk groups with severe condition, determining optimum and effective options for prevention and treatment of disease, retention of time and money for the survey, but also an ability for using the data for their correlation with external factors the environment (ecology, nutrition, addictions, vaccinations, pharmacotherapy, etc.).

\section{References}

1. Zilber, A.P. Objectification of the patient's severity.Proc: Zilber AP (Eds) Critical care of the medicine. (1995) Petrozavodsk: IzdPetrozavod Univ pp: 131-146.

2. Bone, R.C. Why new definition of sepsis and organ failure are needed. (1993) Am J Med 95: 348-350.

3. Fery-Lemonniere, E., Landais, P., Loirat, P. Evaluation of severity scoring systems in ICUs - translation, conversion and definition ambiguities as a source of inter-observer variability in APACHE II, SAPS and OSF. (1995) Intensive Care Med 21(4): 356-360.

4. Belousov, A., Belousova, E., Maloshtan, V. New universal system for assessing the physiological state of the organism (PHUAS) // Pain (2008) PainkillerandIntensiveCare Kiev 2 (d): 22-25.

5. Genkin, A.A. [The OMIS program package as an instrument for the systems analysis of clinico-laboratory data (on the 10th anniversary of the scientific research firm Intellectual Systems). Obolochka meditsinskikh intellektual'nykh sistem=The covering of medical intellectual systems]. (1999) Klin Lab Diagn 38-48. 